\title{
PENGEMBANGAN PROGAM MUHADATSAH USBU'IYYAH DI PONDOK PESANTREN AS-SAKIENAH SLIYEG INDRAMAYU
}

\author{
Rohmawan \\ Institut Agama Islam Negeri (IAIN) Syekh Nurjati Cirebon \\ Email: rohmawan1707@gmail.com \\ Hasan Saefuloh \\ Institut Agama Islam Negeri (IAIN) Syekh Nurjati Cirebon \\ Email: hazansf@yahoo.com \\ Durtam \\ Institut Agama Islam Negeri (IAIN) Syekh Nurjati Cirebon \\ Email: zisandurtam@gmail.com
}

Diterima tanggal 29-11-2021

Publish tanggal 16-12-2021

\begin{abstract}
Abstrak
Penelitian ini bertujuan untuk mengetahui pengembangan program muhadatsah usbu'iyyah di pondok pesantren As-Sakienah Sliyeg-Indramayu. pondok pesantren As-Sakienah Sliyeg-Indramayu, adalah salah satu lembaga yang menerapkan lingkungan linguistik dan telah diterapkan sejak lama. Santri, ustadz, dan masyarakat di dalamnya harus berbicara bahasa Arab setiap hari. Dan juga termasuk didalamnya terdapat kegiatan bahasa untuk membantu mereka berbicara bahasa Arab, seperti Muhadloroh, pidato, berbicara, dan festival bahasa. Dan mereka harus terbiasa berbicara bahasa Arab di lingkungan ini. Penelitian ini adalah penelitian $R \& D$ (Research and Development). Hasil penelitian ini: 1). Kurikulum pengajaran di pondok pesantren As-Sakienah Sliyeg-Indramayu menggunakan dua bahasa, yaitu bahasa Arab dan bahasa Inggris, dan ini menjadi salah satu penyebab kekurangan dan penurunan kinerja pengajaran program percakapan bahasa Arab mingguan. 2). Peneliti menyimpulkan bahwa tujuan pengajaran keterampilan berbicara adalah mempelajari bunyi-bunyi bahasa Arab dan bunyi-bunyi dialek dan sejenisnya, serta mengungkapkan pikirannya dengan menggunakan sistem pembentukan kata yang benar dalam bahasa Arab, khususnya dalam bahasa Arab. bahasa lisan, serta untuk membiasakan santri dengan aturan berbicara, mendengarkan dan memperhatikan kata-kata orang yang berbicara Untuk beberapa dari mereka, bahkan jika mereka tidak setuju dengannya dalam pendapat dan
\end{abstract}


ketekunan. 3) Tujuan dari program pengajaran percakapan bahasa Arab mingguan di pondok pesantren As-Sakienah Sliyeg-Indramayu, agar santri dapat mempelajari pidato sehari-hari dalam bahasa asing, khususnya bahasa Arab. Dengan menambahkan percakapan bahasa Arab asing di setiap minggu, santri ustadz dapat berbicara dalam bahasa itu dan menciptakan lingkungan linguistik di lembaga itu. Dan kemudian kami membuat kalender pada tambahan percakapan ini.

\title{
Kata Kunci: Pengembangan Program Bahasa Arab, Muhadatsah Usbu'iyyah.
}

\begin{abstract}
This study aims to determine the development of the usbu'iyyah muhadatsah program at the As-Sakienah Islamic Boarding School, Sliyeg-Indramayu. Pondok Pesantren As-Sakienah Sliyeg-Indramayu, is one of the institutions that implements a linguistic environment and has been applied for a long time. Students, teachers and society in it must speak Arabic every day. It also includes language activities to help them speak Arabic, such as Muhadloroh, speeches, speeches, and language festivals. And they have to get used to speaking Arabic in this environment. This research is an R\&D (Research and Development) research. The results of this study: 1). The teaching curriculum at the As-Sakienah Islamic Boarding School SliyegIndramayu uses two languages, namely Arabic and English, and this is one of the causes of the shortage and decline in teaching performance of the weekly Arabic conversation program. 2). The researcher concludes that the purpose of teaching speaking skills is to learn Arabic sounds and dialect sounds and the like, and to express their thoughts using the correct word formation system in Arabic, especially in Arabic. spoken language, as well as to familiarize students with the rules of speaking, listening and paying attention to the words of the person speaking For some of them, even if they do not agree with him in opinion and perseverance. 3) The aim of the weekly Arabic conversation teaching program at the As-Sakienah Islamic Boarding School, Sliyeg-Indramayu, is that students can learn everyday speech in foreign languages, especially Arabic. By adding foreign Arabic conversations each week, teacher students can speak the language and create a linguistic environment in the institution. And then we create a calendar on this additional conversation.
\end{abstract}

Keywords: Development of the Arabic Language Program, weekly conversation 


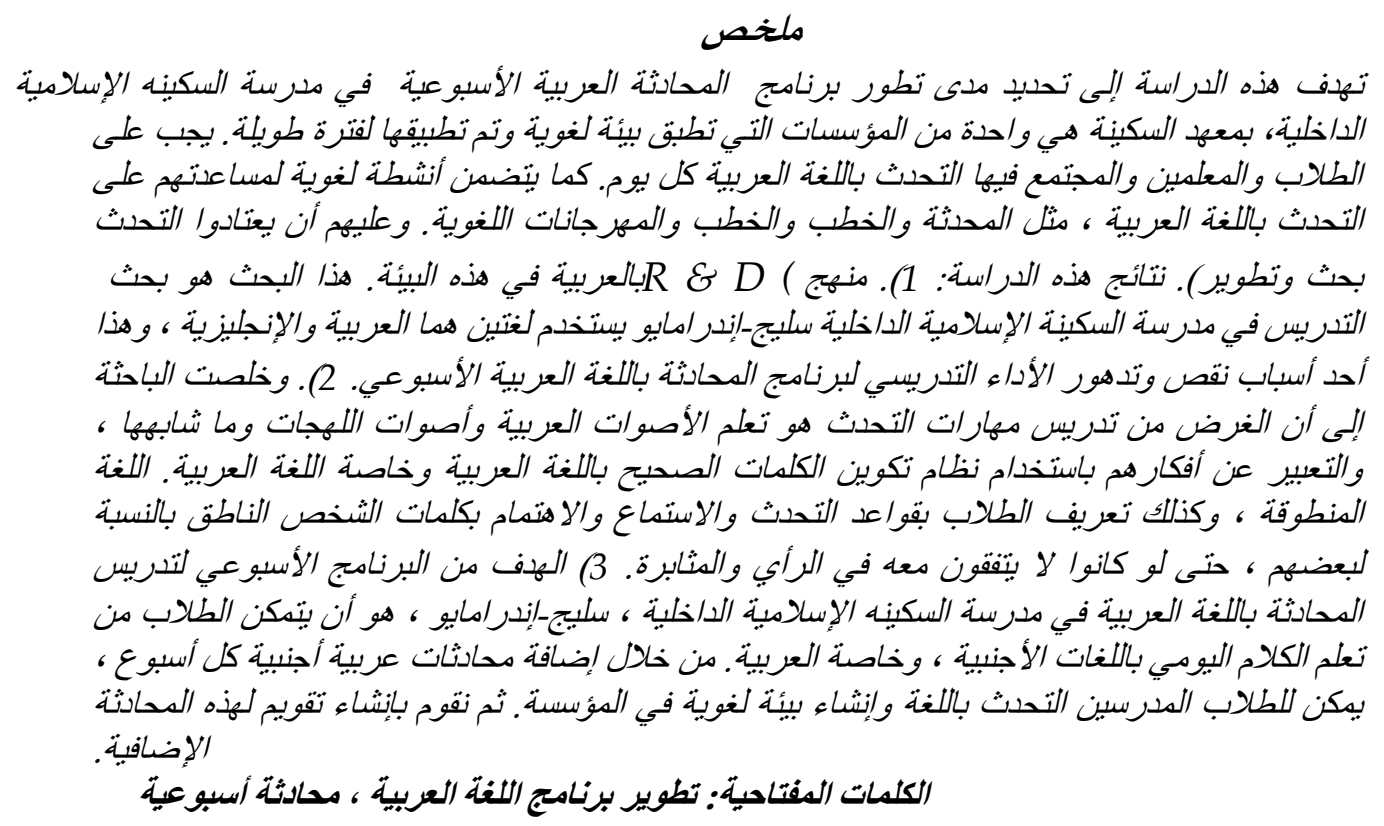

\section{Pendahuluan}

Bahasa adalah alat komunikasi antara individu dan orang lain (Susiawati, 2018). Bahasa adalah cara untuk mengekspresikan apa yang ada di hati dan pikirannya kepada penerima. Bahasa adalah cara paling penting untuk berbicara dengan orang lain (Iswanto, 2015). Oleh sebab itu memainkan peran bahasa sangatlah penting dalam kehidupan manusia (Djago Tarigan dkk, 2015). Karena, bahasa adalah simbol vokal yang secara acak, mungkin semua orang dalam kultur tertentu, atau orang lain yang telah mempelajari kultur ini, untuk datang dan berinteraksi satu sama lain (Brown, 1994). Jelas bahwa kemampuan kemampuan bahasa manusia tergantung pada jumlah dan kualitas kosakata mereka. Semakin banyak kosakata yang kita miliki, semakin besar kemungkinan kemampuan bahasa (Djago Tarigan dkk, 2015).

Kosakata adalah kumpulan kata-kata dalam bahasa atau seperangkat katakata yang akan membentuk bahasa (Djago Tarigan dkk, 2015). Menguasai kosakata sangatlah mendasar dalam pembelajaran bahasa, salah satunya bahasa Arab. Hal ini karena kosakata adalah cara atau tangga untuk dapat menguasai empat kemampuan bahasa (Suprihatin, Elmubarok, \& Busri, 2017). Bahasa Arab sebagai bahasa asing di Indonesia, yang dipelajari di lembaga pendidikan formal dan informal mulai dari sekolah dasar, sekolah menengah dan sekolah menengah hingga tingkat pendidikan tinggi. Dalam pembelajaran bahasa, penguasaan kosakata ini diterapkan pada kemampuan mendengarkan, berbicara, membaca dan menulis. Berbicara adalah reproduksi bahasa selama komunikasi, dan suara 
bahasa yang dihasilkan mungkin bisa mengonontrol bahasa dengan mudah untuk bisa menulis hal-hal yang akan keluar dari pikiran sendiri (Abdel Bari, 2010).

Berbicara adalah warna aktivitas linguistik bagi kaum muda, seperti anak tua yang belajar bahasa, bahwa ekspresi lisan lebih awal dari editorial. Jadi orang mempunya kelebihan menggunakan ucapannya daripada menulis, dengan kata lain mereka berbicara lebih dari yang mereka tulis, dan ini adalah bukti bahwa ucapan adalah bentuk utama komunikasi bagi manusia (Abdul Hadi, dkk, 2003).

Keterampilan berbicara adalah kemampuan untuk mengekspresikan pendapat, ide dan perasaan atau pita lidah kepada oarang lain baik secara langsung maupun tidak langsung. Berbicara paling sering digunakan dalam berkomunikasi dengan orang lain. Ini dikenal sebagai sarana untuk membantu orang memenuhi tuntutan kehidupan sosial seperti yang dipersyaratkan dengan mengkomunikasikan bahwa berbicara di antara ahli bahasa adalah setiap kata benda yang dibicarakan itu jelas (Yad, 1980).

Pondok Pesantren As-Sakienah Sliyeg-Indramayu yang salah satunya memiliki program mingguan bahasa Arab dan Inggris yang saat ini sangat banyak diminati oleh kalangan masyarakat. Dimana para santrinya setiap hari diwajibkan untuk berkomunikasi dengan menggunakan bahasa Arab dan inggris pada saat bersamaan telah menerapkan Muhaddatsah yakni mengkondisikan para santri untuk selalu berdialog bahasa Arab dalam pengajaran serta menciptakan lingkungan yang mendukung dalam pembiasaan komunikasi berbahasa arab (Bi'ah Lughowiyah). Dari latar belakang masalah tersebut, maka peneliti memilih judul "Pengembangan Program Muhadatsah Usbu'iyyah di Pondok Pesantren AsSakienah Sliyeg Indramayu."

\section{Metode Penelitian}

Penelitian ini merupakan penelitian R\&D (Research and Development). Menurut Sukmadinata R\&D adalah proses atau langkah untuk mengembangkan produk baru atau meningkatkan produk yang sudah ada, yang dapat dibenarkan. Produk-produk ini tidak selalu dalam bentuk objek atau perangkat, seperti buku, modul, alat bantu pendidikan di kelas atau di laboratorium, tetapi mereka juga dapat menjadi program, seperti perangkat lunak komputer untuk pemrosesan data, pendidikan kelas, perpustakaan, laboratorium, model pendidikan, pembelajaran, pelatihan, bimbingan, evaluasi, manajemen, dll. Dalam penelitian ini menggunakan pendekatan R\&D karena dalam penelitian ini akan menghasilkan produk yang berupa media pembelajaran interaktif mata pelajaran Promosi Statis.

Borg and Gall mengungkapkan ada 10 langkah dalam proses penelitian pengembangan, namun menurut Tim Puslitjaknov prosedur penelitian pengembangan menurut Borg dan Gall dapat dilakukan dengan lebih sederhana 
melibatkan 5 langkah utama, yaitu: (1) Melakukan analisis produk yang akan dikembangkan; (2) Mengembangkan produk awal; (3) Validasi ahli dan revisi; (4) Uji coba lapangan skala kecil dan revisi produk; (5) Uji coba lapangan skala besar dan produk akhir. Langkah-langkah prosedur pengembangan tersebut dapat digambarkan sebagai berikut:

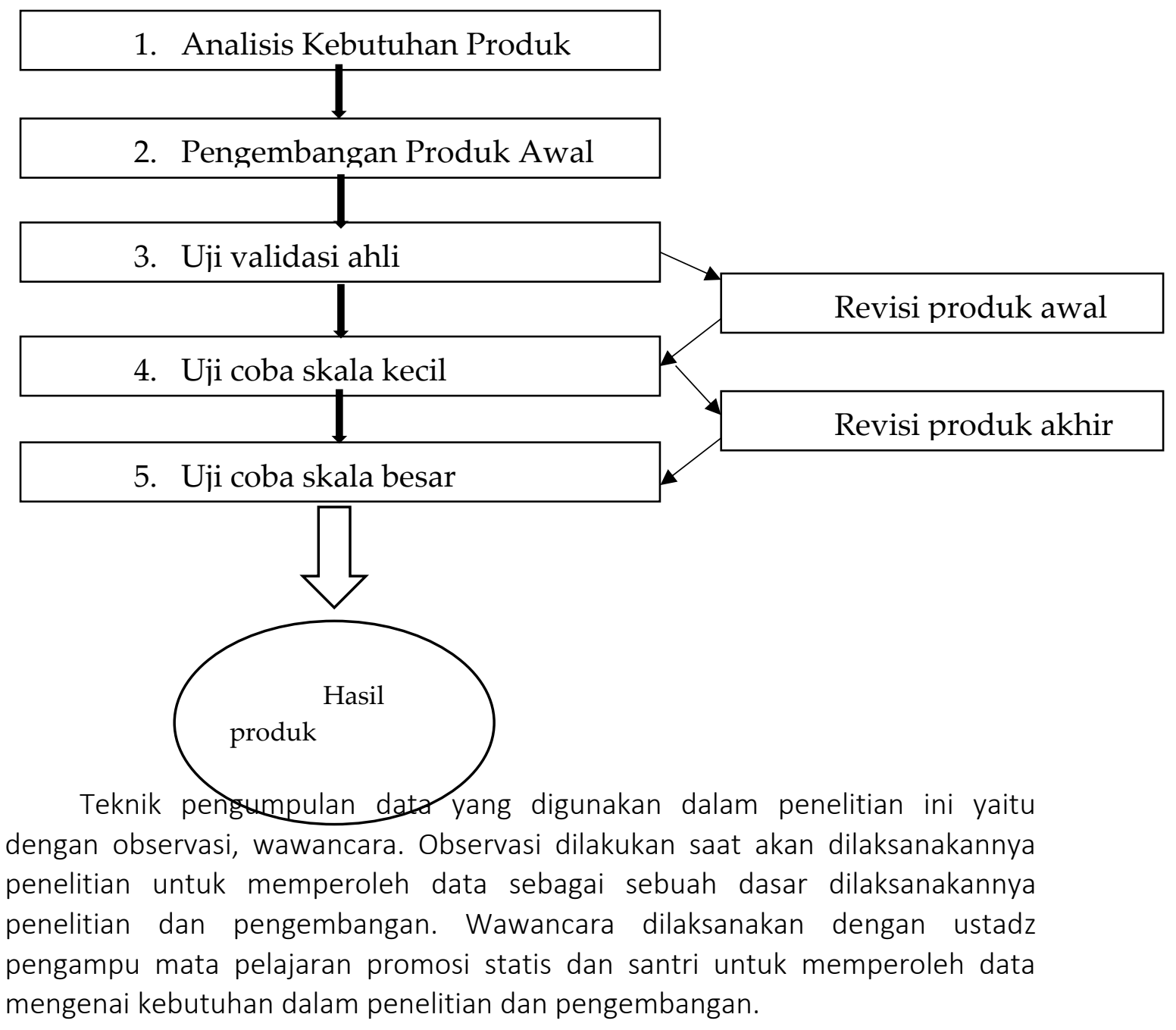

\section{Pengertian Pembiasaan Berbicara Bahasa Arab}

Pembiasaan adalah pengulangan suatu pekerjaan yang dilakukan seseorang. Pembiasaan dalam teori pembelajaran masuk kedalam teori belajar behavioristik. Sedangkan teori bahavioristik yang sesuai dengan penelitian ini adalah teori behavioristic yang di kemukakan oleh pavlop. Dimana teori ini adalah salah satu jenis pembelajaran penting yang digunakan dalam interpretasi dan peningkatan proses pemrolehan bahasa kedua (bahasa asing.) 
Dalam teori ini pavlop menyimpulkan bahwa jika respon yang dikondisikan oleh stimulus asli dan stimulus yang mengirinya. Serta proses ini dilakukan secara berulang-ulang. Kemudian stimulus asli dihilangkan dan tetap mendatangkan stimulus yang mengiringinya saja maka respon yang yang dikondisikan itu akan terjadi.

Teori ini di uji cobakan oleh pavlop pada seekor anjing yang lapar dimana ketika melihat makanan ia mengeluarkan air liurnya. Kemudian pavlop menyajikan makanan diiringi oleh suara bel. Proses itu dilakukan berkali-kali. Setelah itu pavlop hanya membunyikan bel tanpa menyajikan makanan dan pavlop melihat anjing itu mengelurkan air liurnya hanya dengan membunyikan bel. Disini jelas terbukti bahwa prilaku anjing telah berubah karena pengalamannya.

Konsep dasar teori ini adalah:

a. pengkondisian secara klasik;

b. stimulus yang tidak dikondisikan;

c. pengulangan;

d. penguatan;

e. stimulus yang dikondisikan;

f. respon yang tidak dikondisikan;

g. respon yang dikondisikan;

h. pemberian reward dan hukuman;

i. stimulus yang di generalisasikan;

j. diskriminasi;

k. peleburan (Mahmud, 2006).

\section{Pengertian Keterampilan Berbicara}

Berbicara adalah kemampuan mengucapkan bunyi-bunyi artikulasi dan kata-kata untuk mengekspresikan, menyatakan, serta menyampaikan pikiran, gagasan, dan perasaan (Djago Tarigan dkk, 2015). Sedangkan keterampilan berbicara adalah kemampuan mengungkapkan bunyi-bunyi artikulasi atau katakata untuk mengekspresikan pikiran berupa ide, pendapat, keinginan dan perasaan kepada lawan bicara. Dalam makna yang lebih luas, berbicara merupakan sistem tanda-tanda yang dapat didengar dan dilihat yang memanfaatkan sejumlah otot dan jaringan otot tubuh manusia untuk menyampaikan pikiran dalam rangka memenuhi kebutuhannya (Hermawan, 2014).

Keterampilan berbicara meliputi dua hal yakni:

a. Percakapan (Muhaddatsah). 
Percakapan atau dalam bahasa Arab disebut muhadatsah merupakan cara menyajikan bahasa pelajaran bahasa Arab melalui percakapan, dalam percakapan itu dapat terjadi antara ustadz dan murid, dan antara murid dengan murid, sambil menambah dan terus memperkaya pembendaharaan kata-kata yang semakin banyak.

b. Ungkapan Secara Lisan.

Ungkapan secara lisan atau Ta'bir Syafahih adalah latihan membuat karangan secara lisan bertujuan untuk mengembangkan kemampuan pelajar dalam mengutarakan pikiran dan perasaaanya (Izzan,2013).

Adapun tujuan keterampilan berbicara adalah: a. Membiasakan murid bercakap-cakap dengan bahasa yang fasih; b. Membiasakan murid menyusun kalimat yang timbul dari dalam hati dan perasaannya dengan kalimat yang benar dan jelas; c. Membiasakan murid memilih kata dan kalimat, lalu menyusunnya dalam bahasa yang indah, serta memperhatikan penggunaan kata pada tempatnya.

\section{Langkah-langkah Pembelajaran Keterampilan Kalam}

Ada beberapa langkah yang bisa digunakan oleh seorang ustadz ketika mengajarkan keterampilan berbicara antara lain:

Untuk pembelajar pemula (mubtadi') : 1. Ustadz mulai melatih bicara dengan memberi pernyataan yang harus dijawab oleh santri; 2 . Pada saat yang bersamaan santri diminta untuk belajar mengucapkan kata, menyusun kalimat dan mengungkapkan pikiran; 3. Ustadz menustadztkan pertanyaan-pertanyaan yang dujadikan oleh siwa sehingga berakhir membentuk sebuah tema yang sempurna.; 4. Ustadz menyuruh santri menjawab latihan-latihan syawiyah, menghafal percakapan atau menjawab pertanyaan yang berhubungan dengan isi teks yang telah santri baca.

Bagi pembelajar menengah (mutawassith) : 1.Belajar berbicara dengan bermain peran; 2. Berdiskusi tentang tema tersebut; 3. Bercerita tentang peristiwa yang dialami oleh santri (Rosyidi \& Ni'mah, 2000); 4. Bercerita tentang informasi yang

telah didengar dari televisi, radio atau lainnya (Muna, 2011).

Bagi pembelajar tingkat lanjut (mutaqaddim): 1. Ustadz memilihkan tema untuk berlatih kalam; 2. Tema yang dipilih hendaknya menarik dan berhubungan dengan kehidupan santri; 3. Tema jelas dan terbatas; 4. Mempersilahkan santri memilih dua tema atau lebih sampai akhirnya santri bebas memilih tema yang dibicarakan tentang apa yang mereka ketahui (Rosyidi \& Ni'mah, 2000). 


\section{Masalah Dalam Aktivitas Keterampilan Berbicara}

Ada beberapa masalah dalam aktifitas berbicara diantaranya adalah:

a. Santri grogi berbicara karena: khawatri melakukan kesalahan, takut di kritik, malu, khawatir kehilangan muka.

b. Tidak ada bahan untuk di bicarakan : tidak bisa berfikir tentang apa yang mau dikatakan dan tidak ada motivasi untuk mengungkapkan apa yang mau dikatakan

c. Kurang atau tidak ada partisipasi dari santri lainnya, hal ini dipengaruhi oleh beberapa santri yang cenderung mendominasi, yang lain sedikit berbicara.

d. Penggunaan bahasa ibu, merasa tidak bisa berbicara bahasa asing (Rosyidi \& Ni'mah, 2000).

\section{Pengertian Lingkungan Bahasa Arab}

Lingkungan adalah meliputi semua kondisi-kondisi didalam dunia ini yang dalam cara-cara tertentu mempengaruhi tingkah laku kita, pertumbuhan, perkembangan atau life proses (Rosyidi \& Ni'mah, 2000). Sedangkan lingkungan bahasa adalah segala sesuatu yang didengar dan dilihat oleh pembelajar berkaitan dengan bahasa target yang sedang dipelajari (Effendi, 2005).

Lingkungan bahasa Arab sendiri terdiri dari dua macam, yaitu lingkungan bahasa Arab resmi dan lingkungan bahasa Arab non resmi. Setiap dari kedua lingkungan bahasa arab tersebut sangat berperan penting dalam pembelajaran bahasa Arab baik di dalam maupun di luar kelas. Karena segala yang ada disekitar pelajar, baik yang berifat audio atau pun visual akan sangat berpengaruh dalam kesuksesan pembelajaran bahasa Arab. Maka sangat pentinglah bagi kita untuk mengetahui apa itu lingkungan bahasa Arab dan perannya yang dapat membantu pembelajaran bahasa Arab bagi pembicara non asli (Mabruroh, 2018). penciptaan lingkungan berbahasa arab tidak lain adalah untuk: 1. Membiasakan dan membisakan sivitas akademik dalam memanfaatkan bahasa Arab secara komunikatif, melalui praktik percakapan (Muhaddatsah), diskusi, seminar, ceramah dan berekspresi melalui tulisan; 2. Memberikan penguatan pemerolehan bahasa Arab yang sudah dipelajari; 3. Menumbuhkan kreativitas dan aktivitas berbahasa Arab yang terpadu secara teori dan praktik (Khalifah, 2003).

Adapun untuk mencapai lingkungan bahasa ada beberapa syarat yang harus dipenuhi diantaranya: 1 . bahwa semua pihak terkait dengan lembaga pendidikan seperti, ustadz bahasa Arab, pimpinan, dan tenaga pengajar lain mempunyai sikap positif terhadap bahasa kedua tersebut (bahasa Arab) dan 
punya komitmen yang kuat untuk memajukan pengajaran bahasa Arab sehingga apa yangdiharapkan dari tujuan pengajaran dapat diwujudkan; 2. bahwa adanya beberapa model atau figure di lingkungan bahasa tersebut yang mampu berkomunikasi dengan bahasa Arab tersebut sekalipun tidak ada penutur asli (nathiq bih); 3. tersedianya alokasi dana untuk kelengkapan sarana prasarana yang memadai guna menunjang terciptanya lingkangan arabiyah (Effendi, 2005).

Sedangkan cara lingkungan bahasa dapat terbentuk adalah dengan : a. Adanya kegiatan bahasa; kegiatan bahasa ini bertujuan agar santri memperoleh empat keterampilan bahasa maka sekolah perlu memiliki beberapa komponen diantaranya: 1 . Ada badan yang mengatur jalannya kegiatan bahasa; 2 . Adanya pengawasan dalam setiap kegiatan; 3. Adanya system yang mendudkung jalannya kegiatan bahasa; 4. Adanya sarana yang memadai.; b. Pendapat kaum behaviorisme menganggap bahwa penguasaan bahasa kedua tidak jauh berbeda dengan penguasaan bahasa ibu yang dimana dibutuhkan pembelajaran, pelatihan dan praktik, serta bergantung pada pengaruh eksternal, seperti stimulus yang diikuti oleh respon yang dimana respon tersebut perlu diperkuat; c. Dihya Masqon berpendapat bahwa belajar bahasa Asing dapat dilakukan di lingkungan rumahnya dan diantara lingkungan keluarganya (Masqon, hal: 20-21). Disamping cara membentuk lingkungan berbahasa adapula Faktor-faktor dalam pembentukan lingkungan Arab.

Pengembangan Program Muhadatsah Usbu'iyyah di Pondok Pesantren AsSakienah Sliyeg Indramayu

1. Program Muhadatsah Usbu'iyyah di Pondok Pesantren As-Sakienah Sliyeg Indramayu

a. Sejarah Pondok Pesantren As-Sakienah Sliyeg Indramayu

Pondok Pesantren As-Sakienah, didirikan pada tahun 1990, berlokasi di Jl. Raya Tugu, Dengan modal awal berupa enam lokal bangunan ukuran $7 \times 6$ meter, dan sebidang wakaf dari H. Abdurrohim. Konsep pendidikan yang dikembangkan adalah sistem pendidikan yang mengintegrasikan antara pendidikan sekolah dengan pendidikan pesantren. Sehingga pesantren ini memadukan kurikulum Dikbud/ Depag dan Kurikulum Pesantren.

b. Profile Pondok Pesantren As-Sakienah Sliyeg Indramayu

1. Nama Yayasan : Yayasan Islam Arrahimiyah (YASIRA)

2. Nama Pesantren : AS-SAKIENAH

3. NS. Pesantren : 512321216034

4. Alamat : Jln. Raya Tugu

5. Ds / Kel :Tugu 
6. Kecamatan : Sliyeg

7. Kabupaten : Indramayu

8. Propinsi : Jawa barat

9. Kode Pos : 45281

10. Telp : : (0234) 353064

11. Fax : (0234) 5357047

12. Tahun berdiri $\quad: 1411 \mathrm{H} / 1990 \mathrm{M}$

13. Badan Hukum : Ya

14. Tipe Pesantren : Ashriyah / Modern

15. Ketua Yayasan : KH. Afandi Ismail

16. Pimpinan : H. Mukhtar Ghozali Ali

Visi Pondok Pesantren As-Sakienah

"Menjadi lembaga yang unggul dan berkualitas, baik dibidang spiritual maupun intelektual."

Misi Pondok Pesantren As-Sakienah

Untuk mencapai visi tersebut, perlu dijabarkan menjadi beberapa misi. Adapun misi Pondok Pesantren As-Sakienah sebagai berikut:

- Mencetak santri yang 'alim dan sholeh.

- Mencetak calon pendidik yang profesional.

- Mencetak kader pemimpin umat yang berdedikasi.

- Mencetak santri yang beriman, berilmu dan berakhlak al-karimah. (Sumber Data: Dokumen Pondok Pesantren As-Sakienah)

2. Model Program Muhadatsah Usbu'iyyah di Pondok Pesantren As-Sakienah Sliyeg Indramayu

a. Model Program Muhadatsah Usbu'iyyah

Berdasarkan wawancara dengan Mudir Ma'had As-Sakienah Modern Indramayu pada 19 Maret 2021, ia mengatakan bahwa program percakapan mingguan di Ma'had As-Sakienah Modern 
Indramayu dilakukan 2 kali dalam seminggu. Kemudian alam sebuah program dibagi menjadi tiga bagian:

1) Persiapan

Adapun program kosakata, ceramah, percakapan dan kompetisi bahasa Arab, kamar mayat lembaga adalah persiapan, yang membuktikan langkah keseluruhan, dan tujuannya akan dibersihkan dengan strategi program bahasa.

2) Peraturan

Mekanisme yang dilakukan oleh sebuah lembaga melalui pembentukan Komite Bahasa Arab adalah Departemen Pendidikan. Departemen Pendidikan berkontribusi pada program bahasa Arab.

3) Pelaksanaan

Dalam program eksekutif adalah proses pengembangan antusiasme pada program bahasa Arab. Dia harus menjadi ustadz dalam bahasa Arab dalam setiap program yang dia lakukan.

4) Evaluasi

Pengawasan atau evaluasi yang telah dilakukan suatu program pada akhirnya adalah saran kepada santri dengan kalender semua aktivitas bahasa bahasa dan menulis.

b. Rancangan Pelaksanaan Program Muhadatsah Usbu'iyyah

Rencana Pengembangan program Mingguan Pembelajaran Muhadatsah Bahasa Arab di Pondok Pesantren Moderen As-Sakinah Tugu Sliyeg Indramayu

\begin{tabular}{|c|c|c|}
\hline omor & Kategori & Keterangan \\
\hline 1 & $\begin{array}{l}\text { Program Mingguan } \\
\text { Pembelajaran Muhadatsah Bahasa } \\
\text { Arab }\end{array}$ & $\begin{array}{l}\text { Program ini berupa } \\
\text { kegiatan muhadatsah }\end{array}$ \\
\hline 2 & $\begin{array}{l}\text { Waktu Program Mingguan } \\
\text { Pembelajaran Muhadatsah Bahasa } \\
\text { Arab dilaksanakan }\end{array}$ & ${ }_{\text {Maret- April } 2021}$ Bulan \\
\hline 3 & $\begin{array}{l}\text { Tujuan Program Mingguan } \\
\text { Pembelajaran Muhadatsah Bahasa } \\
\text { Arab }\end{array}$ & $\begin{array}{l}\text { Untuk meningkatkan } \\
\text { muhadtsah santri } \\
\text { Untuk }\end{array}$ \\
\hline
\end{tabular}




\begin{tabular}{|c|c|c|}
\hline & & $\begin{array}{l}\text { mengembangkan } \\
\text { program muhadatsah }\end{array}$ \\
\hline 4 & $\begin{array}{l}\text { Materi Program Mingguan } \\
\text { Pembelajaran Muhadatsah Bahasa } \\
\text { Arab }\end{array}$ & 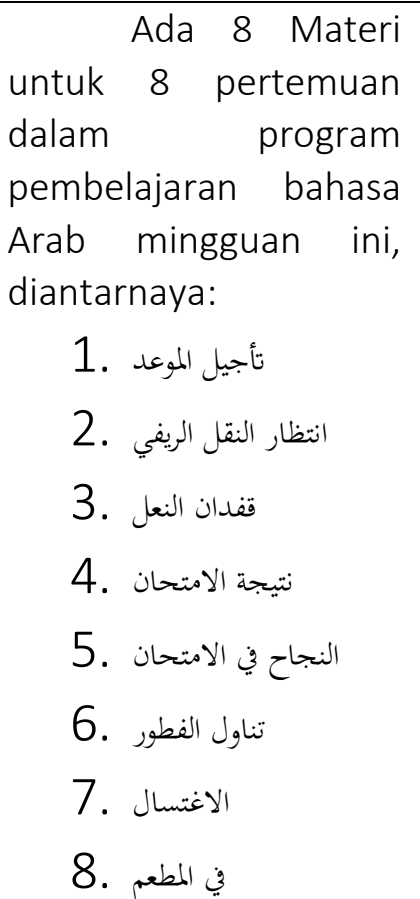 \\
\hline 5 & $\begin{array}{l}\text { Langkah-langkah Program } \\
\text { Mingguan Pembelajaran } \\
\text { Muhadatsah Bahasa Arab }\end{array}$ & $\begin{array}{l}\text { 1. Pengajar berdiri } \\
\text { didepan santri } \\
\text { dengan } \\
\text { memegang buku } \\
\text { muhadatsah; } \\
\text { pengajar harus } \\
\text { terlebih dahulu } \\
\text { menguasai judul } \\
\text { yang akan } \\
\text { diajarkan dan } \\
\text { menguasai } \\
\text { segala aspeknya } \\
\text { Pastikan bahwa } \\
\text { setiap santri } \\
\text { juga telah } \\
\text { membawa buku } \\
\text { Muhadatsah }\end{array}$ \\
\hline
\end{tabular}




\begin{tabular}{|c|c|c|}
\hline & & $\begin{array}{l}\text { 3. Pertama-tama } \\
\text { mintalah agar } \\
\text { para santri } \\
\text { menutup } \\
\text { bukunya } \\
\text { masing-masing } \\
\text { lalu berikanlah } \\
\text { contoh } \\
\text { pengucapan } \\
\text { percakapan } \\
\text { tersebut } 4 \text { kali } \\
\text { 4. Setelah itu beri } \\
\text { kesempatan } \\
\text { pada santri } \\
\text { untuk } \\
\text { mengulangi } \\
\text { sendiri }\end{array}$ \\
\hline 6 & \begin{tabular}{ll}
\multicolumn{1}{c}{ Evaluasi } & Program \\
Mingguan & Pembelajaran \\
Muhadatsah Bahasa Arab
\end{tabular} & $\begin{array}{lr} & \text { Pengaja } \\
\text { r dapat melatih } \\
\text { santri lebih } \\
\text { lanjut dengan } \\
\text { drill. Pilihlah } \\
\text { struktur yang } \\
\text { bagus dan } \\
\text { tentunya } \\
\text { pengajar telah } \\
\text { menyiapkan } \\
\text { beberapa kata- } \\
\text { kata untuk } \\
\text { pengganti dari } \\
\text { obyek yang } \\
\text { akan dipergunakan. }\end{array}$ \\
\hline
\end{tabular}

(Sumber: Modul pengembangan program Muhadatsah Usbu'iyyah)

3. Kelebihan Model Program Muhadatsah Usbu'iyyah di Pondok Pesantren AsSakienah Sliyeg Indramayu 
Kelebihan Model Program Muhadatsah Usbu'iyyah di Pondok Pesantren As-Sakienah Sliyeg Indramayu ini berdasarkan penilaian auditor, kelebihan dari program pendidikan percakapan bahasa arab ini adalah telah menjadi materi perbendaharaan kata dalam kehidupan sehari-hari. percakapan dan mudah diterapkan untuk santri karena perannya yang cepat dalam semua aktivitas santri.

Program Muhadatsah Usbu'iyyah dilengkapi dengan teknik pengajaran yang akan memudahkan ustadz dalam menyampaikan materi mingguan terupdate. Selain itu, kekurangan dari tutorial ini berdasarkan kecermatan: Penulisan materi percakapan tidak menggunakan formulir.

4. Kekurangan Model Program Muhadatsah Usbu'iyyah di Pondok Pesantren As-Sakienah Sliyeg Indramayu

Kekurangan dari program ini:

1. Santri merasa kesulitan jika santri tidak mengetahui apa yang dikatakan di antara mereka tidak sesuai untuk mencapai makna

2. Ustadz merasa kesulitan jika santri yang tidak melakukan program percakapan bahasa arab mingguan ini karena ustadz tidak dapat menemani atau menemani semua santri sepanjang waktu.

\section{Kesimpulan}

Dari Hasil penelitian yang peneliti paparkan sebelumnya, peneliti memperoleh hasil sebagai berikut: berdasarkan hasil observasi langsung, peneliti mengetahui bahwa kurikulum pengajaran di Pondok Pesantren As-Sakienah Sliyeg Indramayu menggunakan dua bahasa, yaitu bahasa Arab dan bahasa Inggris, dan hal ini menjadi salah satu penyebab kekurangan dan ketidaklengkapan dalam pelaksanaan pengajaran. program percakapan bahasa Arab mingguan, dan lainnya tidak meningkatkan penguasaan kosakata ilmiah santri dalam bahasa Arab sementara mereka berbicara bahasa Arab dalam bahasa sehari-hari mereka tanpa programmer dan metodologi, peneliti menyimpulkan bahwa tujuan pengajaran keterampilan berbicara adalah mengucapkan untuk mempelajari bahasa Arab dan bunyi-bunyi dialek dan sejenisnya, serta mengungkapkan pemikirannya dengan menggunakan sistem pembentukan kata yang benar dalam bahasa Arab, khususnya dalam lisan. bahasa, serta untuk membiasakan santri dengan aturan berbicara, mendengarkan dan memperhatikan kata-kata orang yang berbicara Untuk beberapa dari mereka, bahkan jika mereka tidak setuju dengannya dalam pendapat dan ketekunan, dan 
Adapun hasil pelaksanaan program Muhadatsah Usbu'iyyah di Pondok Pesantren As-Sakienah Sliyeg Indramayu adalah mahasantri yang dapat mempelajari pidato sehari-hari dalam bahasa asing khususnya bahasa Arab. Dengan menambahkan percakapan bahasa asing bahasa Arab di setiap minggu, santri dapat berbicara dengan ustadz itu. Bahasa dan pembentukan lingkungan kebahasaan di lembaga itu. Dan kemudian kami mengevaluasi penambahan percakapan ini, dan (4) Kelebihan Program Muhadatsah Usbu'iyyah di Pondok Pesantren As-Sakienah Sliyeg Indramayu ialah Program pendidikan percakapan bahasa Arab mingguan ini dilengkapi dengan teknik edukasi yang akan memudahkan ustadz dalam menyampaikan materi percakapan mingguan. Selain itu, kekurangan dari program ini adalah berdasarkan progressing: Penulisan materi percakapan tidak menggunakan formulir. Dan kekurangan yang lain dari program Muhadatsah Usbu'iyyah adalah santri merasa kesulitan jika santri tidak tahu apa yang mereka bicarakan sehingga tidak cocok untuk mencapai persimpangan. Dan ustadz akan merasa kesulitan jika santri yang tidak melakukan program percakapan bahasa arab mingguan ini karena ustadz tidak dapat menemani atau menemani semua santri sepanjang waktu.

\section{Daftar Pustaka}

Abd. Wahab Rasyidi \& Mamluatul Ni'mah. 2000. Memahami Konsep.... Hal. 919217 Ngalim Purwanto, Psikologi Pendidikan. Bandung: Rosda Karya.

Ahmad Izzan, Metodologi Pembelajaran. (Bandung: Humaniora, 2013).

Arikunto, Suharsimi. 2010. Prosedur Penelitian Suatu Pendekatan Praktek. Yogyakarta: Rineka Cipta.

Brown Douglas, 1994. Mendirikan pembelajaran dan pengajaran bahasa. Beirut: Rumah Renaissance Arab.

Dihyah Masqon, al-Lughah al-Arabiyyah: Ta'limuha, wa Ta'alumuha fii Indunisia alHaditsah. (Mesir: Qiro'ah Waqiah an-Namudajiyah, TT). Hal. 20-21.

Djago Tarigan dkk, Pengembangan Keterampilan Berbicara. Jakarta: Departemen Pendidikan dan Kebudayaan, TT. Hal. 6

Effendi, Ahmad Fuad. 2005. Metodologi Pengajaran Bahasa Arab. Malang: Misykat.

Iswanto, Pembelajaran Bahasa Arab Dengan Pemanfaatan Teknologi. Arabiyatuna 1(2)

Khalifah, Hasan Ja'far Al. 2003. Fushrilfi Tadris al-Lughoh alArabiyyah. Riyadh: Maktabah ar-Rusyd. 
Mabruroh. 2018. al-Bi'ah al-Lughowiah al-Arobiyah fi Ta'limi al-Lughoh alArobiyah Lighoiri an-Natiqina Biha. El-Ibtikar vol. 7. No. 2.

Maher Shaaban Abdel Bari. 2010. Keterampilan Berbicara dan Kinerja Praktis.

Mahmud, I, Ahmad. 2006. at-Ta'lim Asasuhu wa Nadzoriyatuhu wa Tatbiqotuhu. Mesir: Darr Ma'rifat.

Nabil Abdul Hadi, Abdul Aziz Abu Hashish, Khaled Abdul Karim Basandi. 2003. Keterampilan dalam bahasa dan invertebrate. Oman: Al-Serrah Publishing and Distribution House.

Sugiyono. 2010. Metode Penelitian Pendidikan (Pendidikan Kuantitatif, Pendekatan Kualitatif dan R \& D). Bandung: Alfabeta.

Suprihatin, E., Elmubarok, Z. \& Busri, H. 2017. Pengaruh Menghafal Al-Qur'an Juz 29 Terhadap Penguasaan Kosa Kata dan Keterampilan Membaca Bahasa Arab Kelas. Jurnal Linasul Arab, 6 (1), 38-43.

Susiawati. 2018. Kajian Bahasa Arab dari A Historis hingga Historis.

Tarigan Djago dkk. TT. 2015. Pengembangan Keterampilan Berbicara. Jakarta: Departemen Pendidikan dan Kebudayaan. 